\title{
Conservation value of tropical forests: Distance to human settlements matters more than management in Central Africa
}

\author{
Simon Lhoest ${ }^{\mathrm{a}, *}$, Davy Fonteyn ${ }^{\mathrm{a}}$, Kasso Daïnou ${ }^{\mathrm{a}, \mathrm{b}}$, Laetitia Delbeke ${ }^{\mathrm{a}}$, Jean-Louis Doucet ${ }^{\mathrm{a}}$, \\ Marc Dufrêne $^{\mathrm{a}}$, Jean-François Josso ${ }^{\mathrm{c}}$, Gauthier Ligot ${ }^{\mathrm{a}}$, Johan Oszwald ${ }^{\mathrm{d}}$, Erwan Rivault ${ }^{\mathrm{d}}$, \\ François Verheggen ${ }^{a}$, Cédric Vermeulen ${ }^{\mathrm{a}}$, Achille Biwolée ${ }^{\mathrm{e}}$, Adeline Fayolle ${ }^{\mathrm{a}}$ \\ ${ }^{a}$ Gembloux Agro-Bio Tech, University of Liège, Passage des Déportés 2, 5030 Gembloux, Belgium \\ ${ }^{\mathrm{b}}$ Nature + asbl, Rue Provinciale 62, 1301 Wavre, Belgium \\ ${ }^{\mathrm{c}}$ Association Catharsius, Rue Baudoin 10, 75013 Paris, France \\ ${ }^{\mathrm{d}}$ Department of Geography/Planning, UFR Social Sciences, University of Rennes, Place du Recteur Henri Le Moal CS 24307, 35043 Rennes cedex, France \\ ${ }^{\mathrm{e}}$ Higher School of Teaching Techniques, University of Douala, BP 1872, Douala, Cameroon
}

\section{A R T I C L E I N F O}

\section{Keywords:}

Biodiversity

Conservation value

Tropical forest

Mammal

Dung beetle

Forest allocation

\begin{abstract}
A B S T R A C T
Tropical forests in Central Africa host unique biodiversity threatened by human degradation of habitats and defaunation. Forests allocated to conservation, production and community management are expected to have different conservation values. Here, we aimed to identify the determinants of the conservation value of tropical forests in southeastern Cameroon, by disentangling the effects of forest allocations, proximity to human settlements, and local habitat. We inventoried two taxonomical groups: mammal species with camera traps (3464 independent detection events) and dung beetle species with pitfall traps (4475 individuals). We used an integrated analytical approach, examining both species richness and composition. For both mammals and dung beetles, species richness decreased from the protected area to the community forests, and the logging concession showed intermediate richness. Species richness of both groups was negatively correlated to the proximity to human settlements and disturbance, with a decreasing gradient of body mass and the loss of the most threatened species. The replacement (i.e., spatial turnover) of both mammal and dung beetle species among forest allocations suggest an integration of conservation initiatives to a large number of different sites, with a priority on protected and remote areas of high biodiversity. These results confirm the high conservation value of protected areas and their essential role in conservation strategies, ecologically connected with well-managed production forests with variable conservation value mainly depending on accessibility. Community forests located close to villages are much more degraded but not totally defaunated and still provide bushmeat to local populations.
\end{abstract}

\section{Introduction}

Tropical forests host at least two thirds of the Earth's terrestrial biodiversity (Gardner et al., 2009), while covering only 6 to $7 \%$ of the land surface (Dirzo and Raven, 2003). But intensified anthropogenic activities lead to deforestation (loss of forest cover) and forest degradation (loss of ecosystem services). These threats induce an irreversible and drastic biodiversity loss across tropical ecosystems (Gardner et al., 2009) with major ecological consequences (Malhi et al., 2014; Poulsen et al., 2013).

In explicit geographical zones, planning and zoning processes define several forest allocations with different allowed practices (Oyono et al., 2014). The area allocated to biodiversity conservation has increased since the middle of the twentieth century (Watson et al., 2014). Despite these efforts, protected areas in the tropics are subjected to an erosion of biodiversity (Laurance et al., 2012; Tranquilli et al., 2014) associated with a rapid human population growth at protected area edges (Wittemyer et al., 2008). Covering a major proportion of tropical areas, production forests may also play a buffering role for biodiversity conservation (Clark et al., 2009; Gibson et al., 2011; Nasi et al., 2012; Putz et al., 2012). Responsibly managed production forests (with a management plan and under reduced-impact selective logging) can harbour a level of biodiversity that is similar to those observed in undisturbed or protected forests (D.P. Edwards et al., 2014; Gibson et al., 2011; Putz et al., 2012). But all production forests are not managed equally: companies certified by responsible management standards (e.g., Forest

\footnotetext{
* Corresponding author.

E-mail address: simon.lhoest@uliege.be (S. Lhoest).
} 
Stewardship Council, FSC, or Programme for the Endorsement of Forest Certification, PEFC) are relatively scarce, especially in Central Africa, and many production forests are managed under conventional logging. Engaging local populations in management has also been suggested as an alternative to state-managed conservation in protected areas (Berkes et al., 1994; Duguma et al., 2018; Kellert et al., 2000; Minang et al., 2019). As an alternative to industrial logging in Central Africa, community forests have been shown to contribute to social and economic development with livelihood improvement (Lescuyer et al., 2019). The participation of local communities can improve sustainability if they are aware of the risks of unsustainable management for the long-term provision of goods and services (Blomley, 2013; Maryudi et al., 2012; Ribot, 2003). Different forest allocations pose different threats and opportunities for biodiversity conservation. Thus, the effects of different forest allocations on biodiversity needs to be evaluated (Panlasigui et al., 2018), specifically in Central Africa, among protected areas, production forests, and community forests (Poulsen et al., 2011). Besides forest management, the influence of human settlements on biodiversity also needs to be quantified since intensified human activities, such as hunting, agriculture or artisanal logging, are directly associated to proximity to villages (Beirne et al., 2019) and roads (Kleinschroth et al., 2019). These disturbances modify forest ecosystems at the landscape-scale and at the local-scale of species habitat. Decoupling the effects of these different drivers on different groups and at different scales is of high importance for designing adequate conservation strategies (Poulsen et al., 2011).

Quantifying forest conservation value implies considering taxonomic groups sensitive to environmental disturbance and contributing to major ecological processes, such as mammals and insects (Nichols et al., 2009). On the one hand, mammal species are the main target of hunting, leading to a massive defaunation in Central Africa (Abernethy et al., 2016; Ziegler et al., 2016) and many species of iconic megafauna (such as the chimpanzee, Pan troglodytes) are classified as endangered on the IUCN Red List (www.iucnredlist.org). The extirpation of hunted species leads to empty forests that still appear structurally intact but where most ecological functions are altered: trophic webs are disrupted, seed dispersal is limited hampering tree recruitment and forest regeneration, and other cascading effects (Abernethy et al., 2013; Poulsen et al., 2018; Redford, 1992; Terborgh et al., 2008). On the other hand, insects are key components of tropical forest ecosystems (Nichols et al., 2008). Specifically, dung beetle species are reported as excellent costeffective ecological indicators in tropical biodiversity surveys at various scales (Cajaiba et al., 2017; Gardner et al., 2008; Klein, 1989). They are sensitive to even small disturbances such as reduced-impact or selective logging (Bicknell et al., 2014; Nichols et al., 2007; Nummelin and Hanski, 1989). Dung beetles contribute to a variety of important ecological processes including nutrient cycling and fertilization, plant growth, and seed dispersal (Nervo et al., 2017; Nichols et al., 2008).

Our objective was to identify the determinants of the conservation value of tropical forests in southeastern Cameroon. We specifically aimed to disentangle the effects of (i) forest allocation (protected area, FSC-certified logging concession, and community forest), (ii) proximity to human settlements (roads and villages), and (iii) local habitat (forest degradation, canopy openness and distance to the nearest river) on the richness and uniqueness of local biodiversity. We hypothesized that conservation value is mainly driven by human activities rather than by local habitat characteristics, and specifically by forest management and proximity to human settlements. In northern Republic of Congo, Poulsen et al. (2011) indeed showed a higher influence of human disturbance (hunting, logging) at landscape-level on animal populations than local-scale effects (forest structure, canopy cover, fruit abundance, topographic and floristic changes). Here, we examine the variation in species richness between and within forest allocations (alpha and gamma diversities) for two taxonomic groups inventoried and sampled using appropriate methods: mammal species with camera traps and dung beetle species with pitfall traps. We also examine the uniqueness of species assemblages by (i) partitioning beta diversity (Baselga, 2010) into its turnover component (spatial replacement of species between sites of completely different compositions) and its nestedness component (loss of species between sites), and by (ii) conducting multivariate analysis (ordination) that integrates information on species traits and conservation status. Based on an integrated and comparative analysis of forest biodiversity in the specific landscape of the Dja area, we discuss the lessons learned for reconciling tropical forest conservation and management at a larger scale, in Central Africa.

\section{Material and methods}

\subsection{Study area}

The study was conducted in southeastern Cameroon (latitude varying from $2^{\circ} 49^{\prime}$ to $3^{\circ} 44^{\prime} \mathrm{N}$, longitude from $12^{\circ} 25^{\prime}$ to $14^{\circ} 31^{\prime} \mathrm{E}$, mean altitude of $743 \mathrm{~m}$ ). Forests in this area are assigned to Moist Central Africa (Fayolle et al., 2014). The annual rainfall is approximately $1640 \mathrm{~mm}$ with two distinct rainy seasons and a mean annual temperature of $23.1{ }^{\circ} \mathrm{C}$ (Hijmans et al., 2005).

Cameroon was the first country in Central Africa to implement a national zoning plan and to impose management plans for logging concessions and community forests after the 1994 Cameroonian Forestry Law. Three forest allocations (protected area, logging concession, and community forest) are well represented in Cameroon ( $88 \%$ of the National Forest Estate) and in Central Africa (Fig. 1A and Appendix A), and are adjacent to each other in the study area (Fig. 1B). These areas are diversely affected by industrial and artisanal logging, hunting, and slash-and-burn agriculture activities (Abernethy et al., 2016; Poulsen et al., 2011).

The Dja Biosphere Reserve is the largest protected area in the country, managed for biodiversity conservation and listed as a Habitat/ Species Management Area under IUCN's Protected Area Categories System. It has been listed as a 'Man and Biosphere Reserve' since 1981 and as a UNESCO World Heritage site since 1987. In the core area (526,000 ha), agriculture, gathering and hunting are prohibited. In the buffer zone (approximately 200,000 ha but not precisely delimited yet), local populations can engage in non-industrial sustainable activities (Appendix A).

The logging concession granted to the PALLISCO Company is managed since 2004 under 30-year forest management plans. Timber harvest is highly selective: on average in 2018 , only 0.65 stems and $9.6 \mathrm{~m}^{3}$ were cut per hectare. Out of the 388,949 ha granted to the company, 341,708 ha were certified by the Forest Stewardship Council (FSC) in 2008, committing to best practices for: (i) the economic effectiveness and viability of forest management, (ii) the ecological integrity of the forests through reduced-impact logging, protection of wildlife, protection against pollution, and (iii) the social equity for workers and local populations. User rights are given to bordering populations for deadwood and NTFP collection. Hunting activities are highly regulated (see details in Appendix A).

The community forests (CF) of Medjoh (4964 ha), Avilso (3433 ha) and Eschiambor (5069 ha) are located between the logging concession and the protected area (Fig. 1B). CFs are small forest areas situated along roads and villages and are dedicated to the exclusive use by local communities for timber harvesting, deadwood collection, NTFP gathering, hunting, and agriculture (Appendix A). They are managed via a 'Simple Management Plan' written by the communities themselves and under the supervision of the Forest administration.

\subsection{Biodiversity inventory}

We inventoried mammals and dung beetles using respectively camera traps (Ahumada et al., 2013) and pitfall traps (Larsen and Forsyth, 2005). Sampling sites were distributed in the three forest allocations, at a distance of at least $500 \mathrm{~m}$ from forest edge. In the logging 


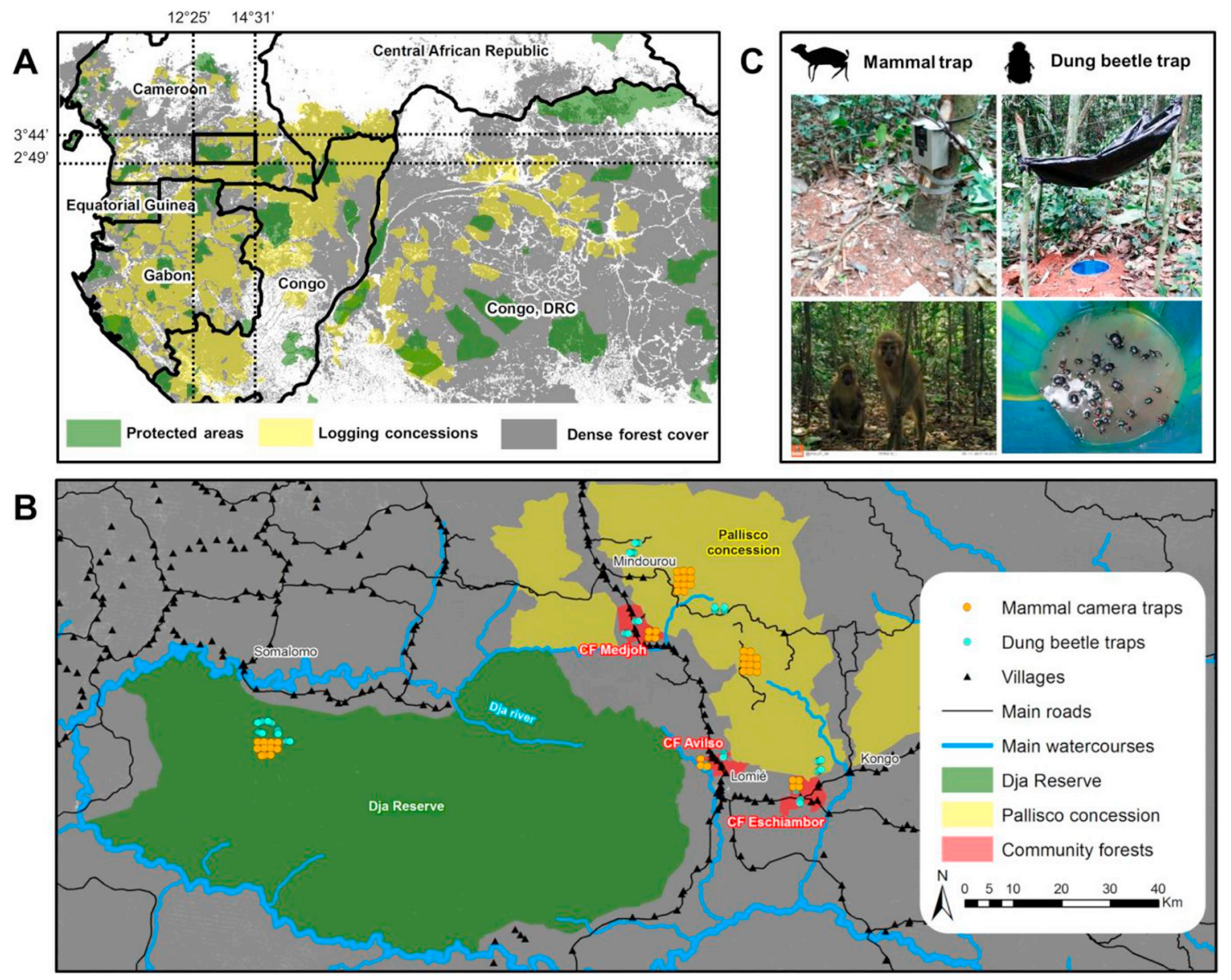

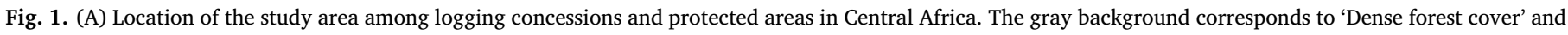

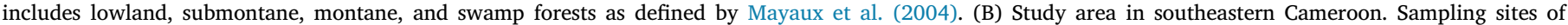

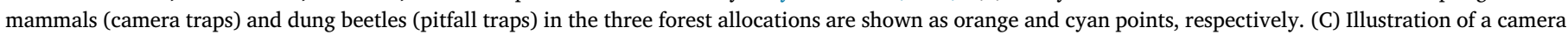

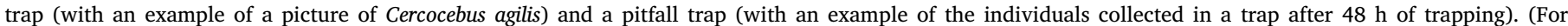
interpretation of the references to color in this figure legend, the reader is referred to the web version of this article.)

concession, areas with different logging histories were evenly sampled to consider biodiversity recovery after logging. In the protected area, all sampling sites were located in the northwestern part of the Reserve (Fig. 1B), where vegetation types are the most similar to the logging concession and community forests (Sonké, 1998).

Mammal species were inventoried using a total of 44 camera traps (model 'Trophy Cam HD Aggressor') set up during the rainy season from February to June 2017 and distributed as follows: one grid of 11 cameras in the protected area, two grids of 11 cameras each in the logging concession (one in a zone logged 23 to 27 years before and the other in a zone logged 17 years before), and one grid of 11 cameras distributed among the three community forests (Fig. 1B). Distances between two camera grids were between 9.3 and $112.3 \mathrm{~km}$. Cameras were installed at a density of one camera per $2 \mathrm{~km}^{2}$ according to the recommendations of the TEAM Network (2011). We placed cameras on trees at $30-50 \mathrm{~cm}$ above ground level and oriented in the direction of animal trails with a sufficient field of view to capture full-body images of mammals. The camera-based monitoring lasted 87-99 days and we standardized the data acquired by each camera to the first 87 inventory days. Herbaceous vegetation was systematically cleared in a radius of $4 \mathrm{~m}$ around the camera, insuring comparable detection probability among all cameras. All cameras were set to take three consecutive shots per trigger. After the inventory, we only used the images acquired by 29 cameras (nine in the protected area, five in the zone logged 20-30 years before, nine in the zone logged 10-20 years before, and six in the community forests) because 15 cameras were either stolen/broken or did not operate properly during the entire inventory period. Images obtained from camera traps were analyzed with the Camera Base software linked to Microsoft Access (Tobler, 2015). Detection events separated by at least $10 \mathrm{~min}$ were considered independent. We identified mammals to species when possible and recorded the number of individuals for each independent detection event. Based on the independent detection events, we produced occurrence and abundance matrices (with species as columns, and either cameras or dates as rows). The mean adult body mass (mean of the body mass given for males and females in Kingdon et al., 2013) and the IUCN status were collated for all inventoried species.

Dung beetles were inventoried using 72 baited pitfall traps from February to April 2016 and distributed along transects of four traps as follows: six transects in the protected area, six transects in the logging concession, and six transects in the community forests (two transects in each community forest). The six transects in the logging concession were distributed as follows: two transects in a zone logged 20 to 26 years before, two transects in a zone logged nine years before, and two transects in a zone logged three years before. To avoid interferences between traps on the same transect, we separated two traps by $250 \mathrm{~m}$, which is four times the distance recommended by Larsen and Forsyth (2005). Distances between two transects were between 1.4 and $116.9 \mathrm{~km}$. Each pitfall trap consisted of a bucket $(280 \mathrm{~mm}$ diameter and $270 \mathrm{~mm}$ deep) buried flush to the ground, containing 11 of odourless soaped water and baited with $16 \mathrm{~g}$ of human faeces, and protected from rain by a plastic tarp of $\sim 1 \mathrm{~m}^{2}$. We collected dung beetles after $48 \mathrm{~h}$ and 
preserved them in 70\% ethanol. We identified dung beetles to species when possible and we assigned a unique morphospecies number when identification was uncertain. After having generated a list of all individuals collected, we produced occurrence and abundance matrices (with species as columns and traps as rows). The mean adult body length was computed for all inventoried species and morphospecies.

\subsection{Correlates of biodiversity}

The values of eight variables were collated for each sampling site, comprising three variables for forest allocations, two variables for proximity to human settlements, and three variables for local habitat. We tested the degree to which these eight variables influenced mammal and dung beetle species richness and composition. For forest allocations, we created three distinct dummy binary variables (i) 'protected area', (ii) 'logging concession', and (iii) 'community forests'. We gave a value of one to the forest allocation to which the sampling site belongs, and null values for the two other forest allocation variables. The proximity to human settlements was computed by: (iv) the distance to the nearest road, and (v) the distance to the nearest village. In terms of habitat variables, we used: (vi) the forest degradation (proportion of pixels classified as degraded forest in the surroundings of each sampling site based on Sentinel-2 satellite imagery and supervised classification; see Appendix B for methodological details), (vii) the percentage of canopy openness above dung beetle traps (mean of five values obtained around each trap with hemispherical photographs; see Appendix B for methodological details), and (viii) the distance to the nearest river. All distances were computed in meters, with the 'Near' tool in ArcGIS software.

\subsection{Biodiversity analysis}

All analyses were performed within the $\mathrm{R}$ environment ( $\mathrm{R}$ Core Team, 2018). We used individual-based rarefaction curves (Gotelli and Colwell, 2001) for each sampling site (camera traps for mammals and pitfall traps for dung beetles) to visualize the variation in species richness within and between sampling sites. We also generated samplebased rarefaction curves (Gotelli and Colwell, 2001) to identify any differences in species richness among forest allocations (package 'vegan', Oksanen et al., 2018). We extracted the species richness (alpha diversity) of each sample-based rarefaction curve for a common number of 435 camera-days for mammals and 24 traps for dung beetles for comparison among forest allocations. We also extracted 10 values of species richness for each sampling site from individual-based rarefaction curves, for a number of individuals (or independent detection events for mammals) equal to $10,20,30,40,50,60,70,80,90$, and 100 (for the curves that reached these numbers of individuals). The consideration of ten values of species richness extracted for ten different numbers of individuals allowed to consider the overall shapes of individual-based rarefaction curves rather than only one value of species richness extracted for only one subjective number of individuals. Then, the relationships between the ten values of extracted species richness (response variables) and the eight variables defined above (correlates of biodiversity for mammal and dung beetle sampling sites separately, predictor variables) were analyzed using the sparse Partial Least Squares method (sPLS, using package 'mixOmics', Lê Cao et al., 2009). This method identifies the best predictor variables for species richness of mammals and dung beetles, based on the criterion of the highest Variable Importance in the Projection (VIP). The main advantage of the method consists in the integration and variable selection combined simultaneously in a one-step analysis. In addition, tested variables can be correlated and can contain NA values. Then, Pearson's correlations were computed to further quantify the individual associations between species richness and relevant predictor variables identified by the sPLS.

Based on the occurrence matrix for both mammals and dung beetles, codifying the presence (1) or absence (0) of species (columns) in forest allocations (rows), we partitioned beta diversity into turnover and nestedness components to compare the whole of forest allocations (multiple-site dissimilarities), and pairs of forest allocations (pairwise dissimilarities) using the package 'betapart' (Baselga and Orme, 2012). Whereas the 'turnover' component represent a spatial replacement of species among sites, 'nestedness' and specifically 'nested' sites indicate that some sites constitute a subset of other species assemblages, where some species were lost or are just absent (Baselga, 2010). For mammals, the same number of camera traps were deployed in each forest allocation but ended into slightly unbalanced design because some cameras were stolen or broken in the field. We then developed a bootstrap approach with 1000 iterations to deal with the unbalanced sampling in the camera trap data. For each iteration, we randomly subsampled for each forest allocation five cameras out of the total number of retrieved cameras (up to nine), and we considered the detected species by these five cameras as present in the forest allocation (whatever the number of detections). This allowed generating an occurrence matrix with four lines, corresponding to the forest allocations, and with 26 columns, corresponding to the mammal species. On this occurrence matrix, we computed the multiple-site dissimilarity (among all forest allocations) and the pairwise dissimilarities (among pairs of forest allocations) with their turnover and nestedness components. We finally computed the average for the two beta diversity components (nestedness and turnover) for the two approaches (multiple-site and pairwise) across the 1000 iterations.

In order to visualize the differences in species composition among forest allocations, we performed a Nonmetric Multidimensional Scaling (NMDS), for mammals and dung beetles separately, based on abundance matrices and Bray-Curtis distances (package 'vegan', Oksanen et al., 2018). Abundance data were square root transformed and submitted to Wisconsin double standardization, due to large and highly variable abundance values. We plotted sites as triangles (with colors corresponding to forest allocations) and species as points (with size proportional to the mean adult body mass for mammals, and mean adult body length for dung beetles), as well as the IUCN conservation status for mammal species. The eight correlates of biodiversity previously mentioned were also plotted as supplementary variables describing sampling sites.

\section{Results}

\subsection{Species richness}

For mammal species, we obtained 3464 independent detection events and identified a total of 26 species (gamma diversity) including iconic species, such as the chimpanzee ( $P$. troglodytes) and the giant pangolin (Manis gigantea). For dung beetle species, we collected and identified 4475 individuals and identified a total of 71 species (gamma diversity) belonging to 21 genera.

Individual-based and sample-based rarefaction curves for both mammals and dung beetles showed a decrease of species richness from the protected area to the community forests, the logging concession being intermediate between the two (Fig. 2). Sample-based rarefaction confirmed the slight differences in richness among forest allocations (Fig. 2B and D). Individual-based rarefaction curves of the logging concession overlapped with those of the other forest allocations, showing that the logging concession could locally be as rich as the protected area or as depauperate as the community forests. For mammals, the alpha diversity of each forest allocation was 23 species in the protected area, 17 species in the zone logged 20-30 years before, 21 species in the zone logged 10-20 years before, and 18 species in the community forests. For dung beetles, the alpha diversity of each forest allocation was 58 species in the protected area, 49 species in the logging concession, and 41 species in the community forests.

For both mammals and dung beetles, sPLS quantified the relationships between the eight correlates of biodiversity and species richness 

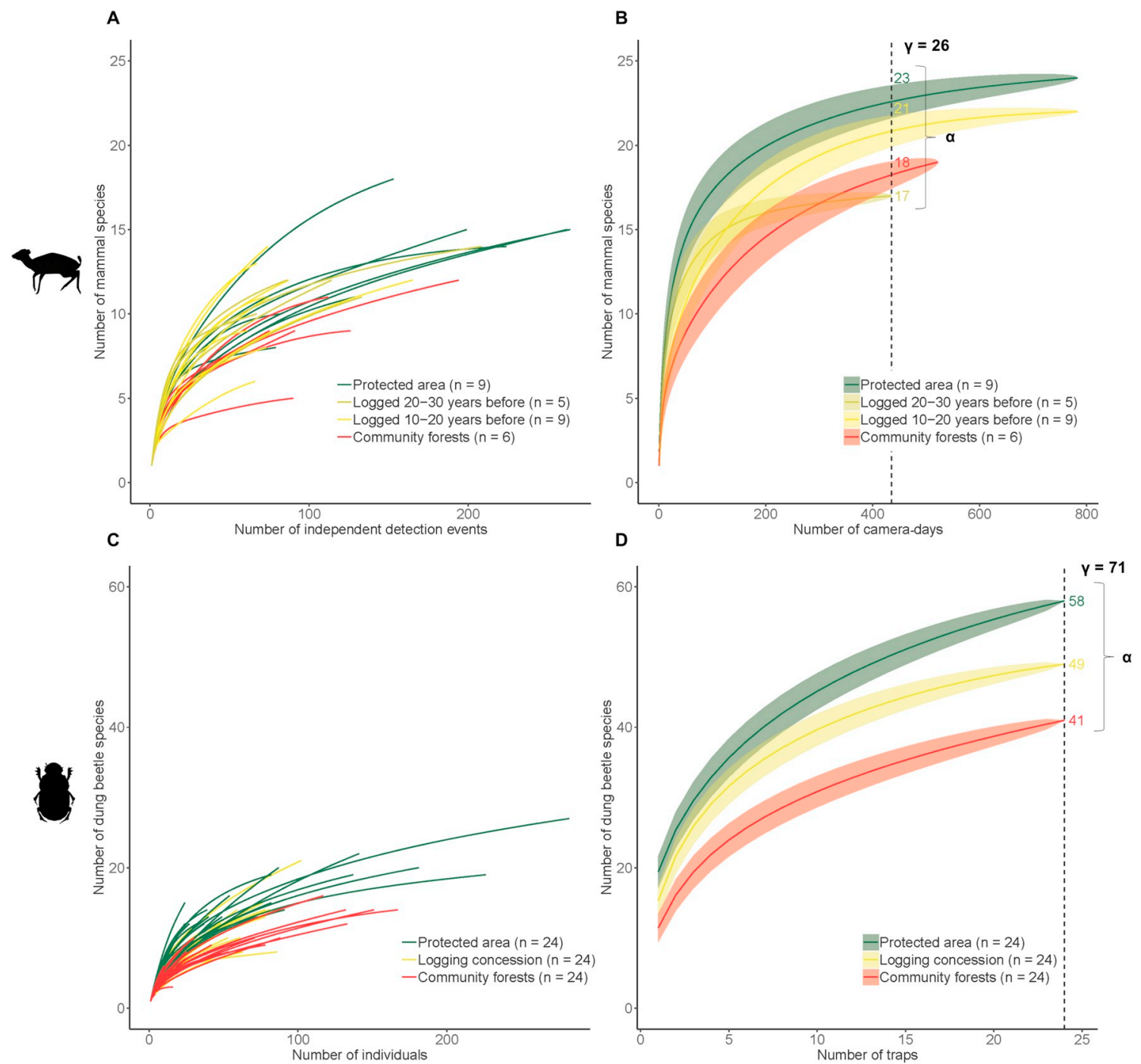

Fig. 2. Individual-based and sampled-based rarefaction curves for mammals (A and B) and dung beetles (C and D). For mammals, the individual-based rarefaction curve considered individuals as the independent detection events (A) and the sampled-based rarefaction curve used camera-days on the horizontal axis (B). The alpha diversity at the scale of each forest allocation is provided for 435 camera-days (B) and for 24 pitfall traps (D). The gamma diversity is also provided and comprises the variety of inventoried species for mammals (B) and for dung beetles (D). The colored shaded areas on sampled-based rarefaction curves (B and D) correspond to the rarefied species richness \pm its standard deviation.

Table 1

Values of VIP (Variable Importance in Projection) obtained from the sPLS explaining mammal and dung beetle species richness with correlates of biodiversity. The two highest VIP values are shown in bold for each taxonomic group. The sign in brackets indicate the direction of the effect of each predictor variable on species richness.

\begin{tabular}{lll}
\hline Correlates of biodiversity $(\mathrm{X})$ & \multicolumn{2}{l}{ Species richness $(\mathrm{Y})$} \\
\cline { 2 - 3 } \cline { 3 - 3 } & Mammals & \multirow{2}{*}{ Dung beetles } \\
\hline Distance to the nearest road & $0.66(+)$ & $\mathbf{1 . 6 5}(+)$ \\
Distance to the nearest village & $\mathbf{1 . 4 8}(+)$ & $0.80(+)$ \\
Distance to the nearest river & $0.24(+)$ & $0.44(-)$ \\
Forest degradation & $0.24(-)$ & $0.50(-)$ \\
Canopy openness & $/$ & $0.34(-)$ \\
Protected area & $0.43(+)$ & $\mathbf{1 . 5 8 ( + )}$ \\
Logging concession & $1.02(-)$ & $0.37(+)$ \\
Community forests & $\mathbf{1 . 7 4 ( - )}$ & $1.21(-)$ \\
\hline
\end{tabular}

values derived from individual-based rarefaction curves for 10 to 100 individuals. The most important predictors of species richness were 'community forests' (VIP $=1.74$, negative correlation) and the distance to the nearest village (VIP $=1.48$, positive correlation) for mammal species; the distance to the nearest road (VIP $=1.65$, positive correlation) and 'protected area' (VIP $=1.58$, positive correlation) for dung beetle species (Table 1 and Appendix C).

\subsection{Species composition}

Beta diversity was partitioned among forest allocations for both mammal and dung beetle species (Fig. 3). Among both mammal and dung beetle species, a strong turnover component was revealed, indicating a replacement of species among sites (for mammals, $\beta=0.25$ with turnover component $=0.15$; for dung beetles, $\beta=0.36$ with turnover component $=0.25$ ). We observed proportionally higher nestedness patterns for mammal species ( $40 \%$ of beta diversity) than for dung beetle species ( $31 \%$ of beta diversity). For mammals, the species composition in the zone logged 20-30 years before the inventory was nested to the species composition in the three other forest allocations, with various levels of turnover. The species composition of the community forests was nested to that of the zone logged 10-20 years before, which was nested to that of the protected area, but showing simultaneously some turnover among forest allocations (list of species in 


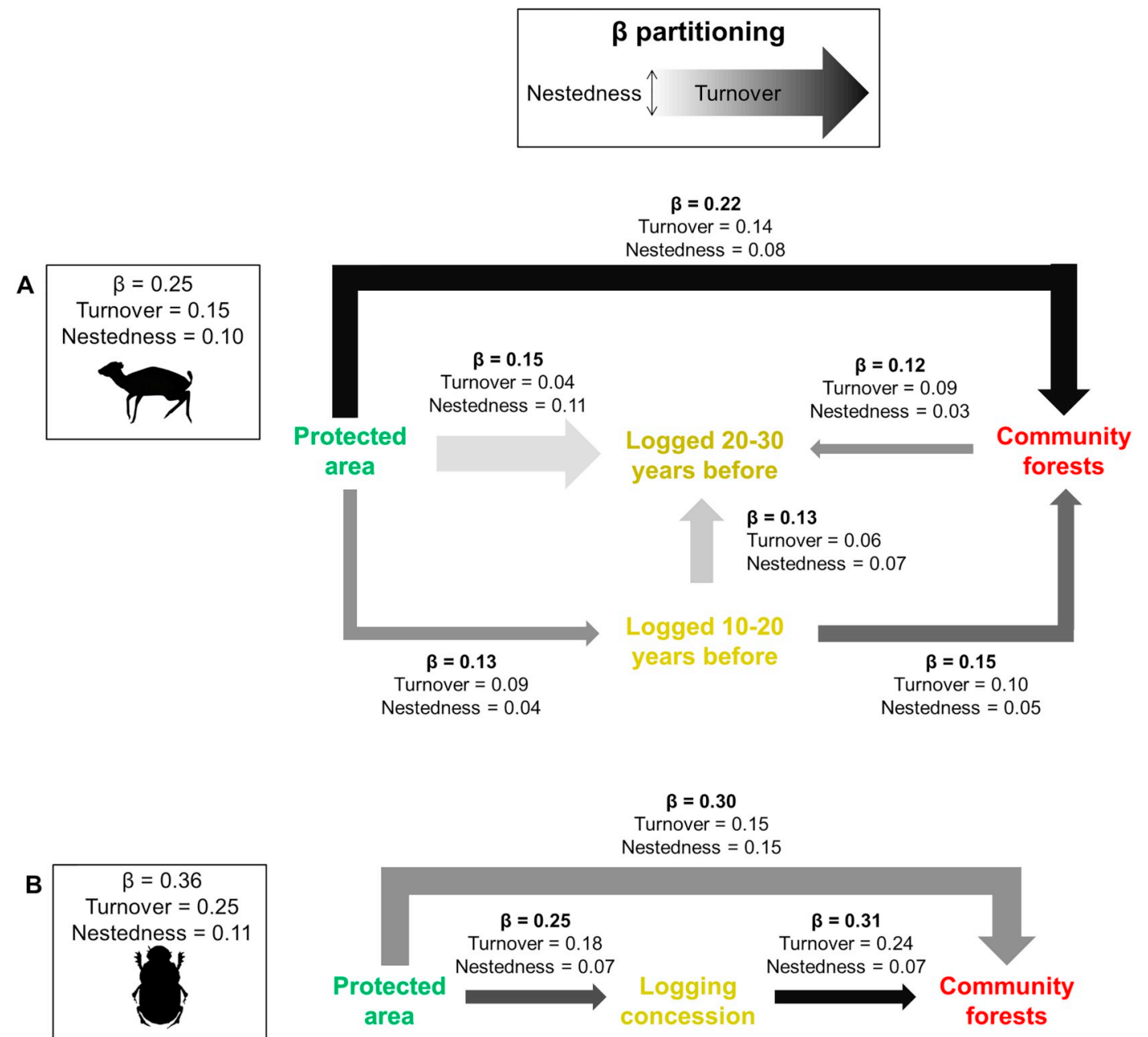

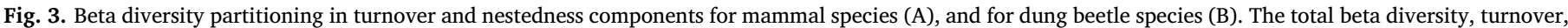

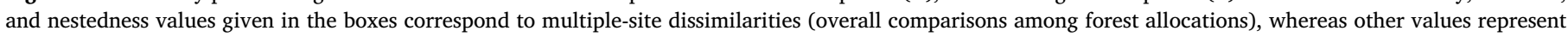

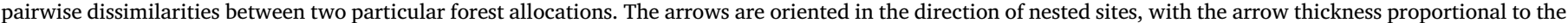
nestedness component, and the arrow darkness proportional to the turnover component.

Appendix D). For dung beetles, the species composition of the community forests was nested to the logging concession, which was nested to the protected area, showing a proportionally higher turnover among forest allocations than mammals (list of species in Appendix E).

A clear distinction in species composition between the protected area and the community forests was identified for both mammals and dung beetles, with an intermediate and heterogeneous composition in the logging concession (Fig. 4). The NMDS for mammal species (Fig. 4A) showed a clear gradient from degraded community forests associated with mainly rodents and small-bodied species (negative scores on NMDS 1) to richer sites with bigger animals in the protected area and in remote areas from villages (positive scores on NMDS 1). A similar gradient was found for dung beetle species along the first axis (Fig. 4B), going from degraded forests with high canopy openness (mainly community forests) to remote areas in the logging concession and in the protected area. NMDS stress value was 0.22 for mammals and 0.24 for dung beetles.

\section{Discussion}

Here, we conducted the first cross-taxonomic assessment of the conservation value of diverse forest allocations in Central Africa, using an integrated framework for biodiversity analysis at the landscape scale. We identified an influence of forest allocation on biodiversity patterns. However, proximity to human settlements and disturbance was the main determinant of forest conservation value. We also found differential responses to forest disturbance across mammals and dung beetles.

\subsection{Limitations of the study}

Due to logistical and financial field constraints, we only sampled a single protected area and a single logging concession and our study design was thus pseudoreplicated (Hurlbert, 1984). Therefore, our results should only be considered and interpreted at the local scale of our study system in its particular social-environmental context in southeastern Cameroon, without any generalization (Cottenie and De Meester, 2003).

The sampling sites were spatially aggregated in grids (camera traps) and transects (pitfall traps) and were not distributed across the entire protected area and logging concession. Then, our sampling sites could not be totally representative of the overall spatial diversity of these two forest allocations. However, it is worth mentioning that we identified a total of 26 mammal species, which is the exact same number of species reported by Bruce et al. (2018) in a larger camera trap grid in the Northern Sector of the Dja Reserve. This protected area is reported to host 109 different mammal species of which 35 species are terrestrial and have a body mass higher than $0.5 \mathrm{~kg}$ (Kingdon, 2015): we missed some species and some of them are extremely rare and possibly locally extinct. 

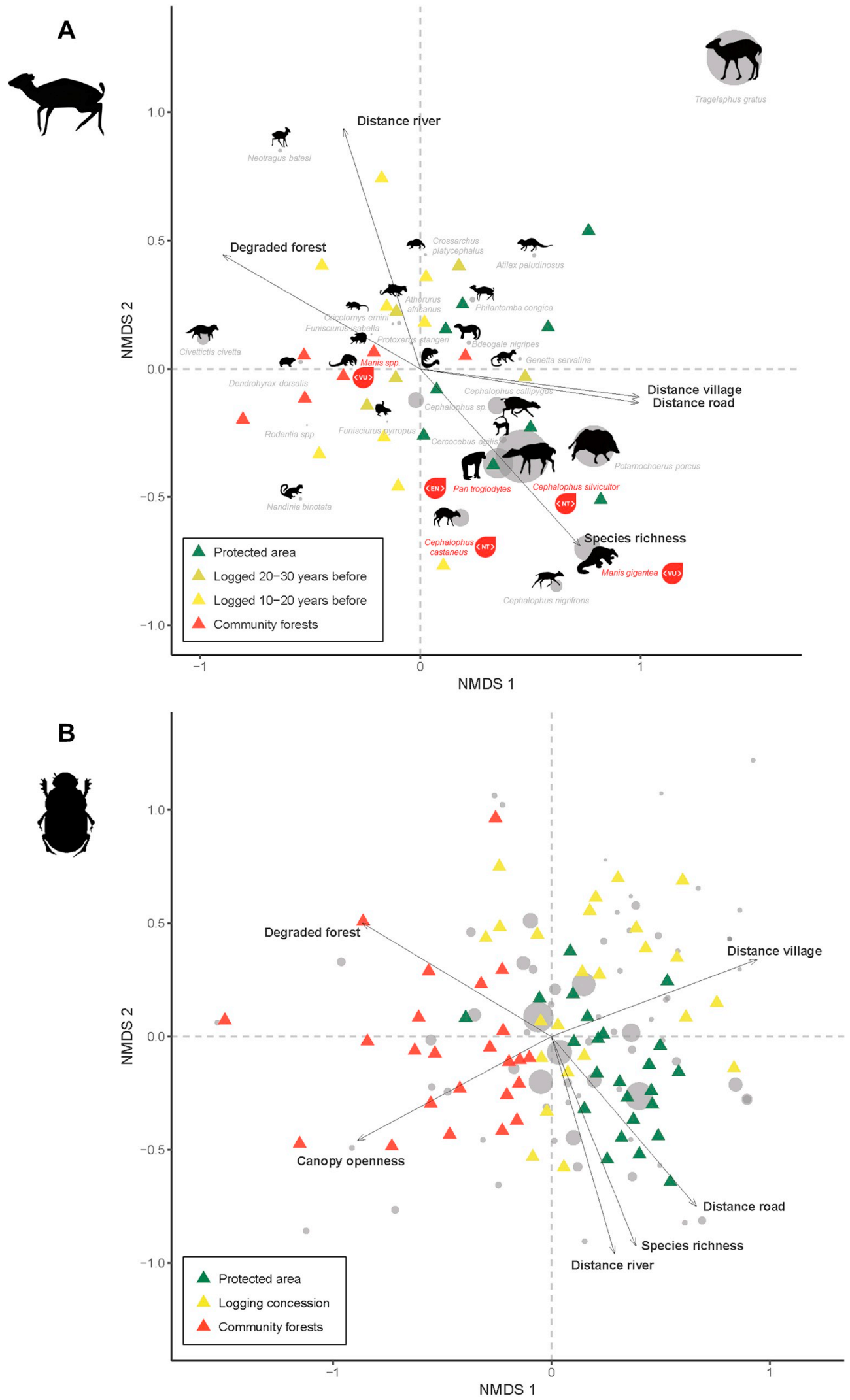

Fig. 4. Nonmetric Multidimensional Scaling of the abundance matrix for mammal species (A) and dung beetle species (B). Colored triangles correspond to sampling sites in different forest allocations. Gray points correspond to species, with point size proportional to the mean adult body mass for mammals (A) or the mean adult body length for dung beetles (B). Arrows show the projection of supplementary variables: distance to the nearest road, distance to the nearest village, distance to the nearest river, forest degradation, canopy openness (only for dung beetles in B), and species richness. In $\mathrm{A}$, mammal species names written in red are listed in the IUCN Red List of Threatened Species as 'Near Threatened' (NT), 'Vulnerable' (VU), or 'Endangered' (EN), others being assessed as 'Least Concern'. Artwork of mammal species in A is adapted from Kingdon et al. (2013). (For interpretation of the references to color in this figure legend, the reader is referred to the web version of this article.)
Our mammal and dung beetle inventory protocols did better detect some species than others, as most inventory techniques do. The ability of camera traps to detect animals is correlated with species body size (Rowcliffe et al., 2011; Tobler et al., 2008). Abundances of small mammal species might have been underestimated, but detection events of mammal species of body mass lower than $1 \mathrm{~kg}$, including mice, rats and squirrels, represented not less than $61 \%$ of all detection events. Concerning pitfall traps, we also used a standardized sampling design which can be used in a wide variety of contexts (Larsen and Forsyth, 2005). All sampling sites were evenly distributed among forest 
allocations (same sample coverage) with the same sampling protocols and similar conditions. We hypothesized comparable detection probability under closed canopies, though slight differences in forest structure and composition. There is no element in our knowledge that was supposed to modify detection probability among forest allocations and we did everything we could not to influence it. For instance, cameras were oriented toward animal trails, with a clear angle, and with cleared herbaceous vegetation, according to the TEAM Network's recommendations (2011). Thus, we consider that the observed differences among forest allocations revealed true differences in mammal and dung beetle species diversity.

\subsection{Differential response of mammals and dung beetles}

For mammal species composition, our results showed a loss of species with proximity to human settlements. It was related to a gradient of decreasing body mass and conservation value, with less large and threatened species remaining near villages. As shown by Beirne et al. (2019), distance away from villages is directly correlated to hunting pressure. The community forests and the zone logged 20-30 years before were composed of a subset of species present in the more diverse sites and were more strongly impacted by hunting practices because of their proximity to villages. The highly detrimental effect of proximity to hunters' access points (i.e. settlements and roads) has been previously demonstrated up to $40 \mathrm{~km}$ inside the forest (Benítez-López et al., 2017), as have the impacts on mammal populations (Benítez-López et al., 2017; Clark et al., 2009; Koerner et al., 2017; Laurance et al., 2006). In the logging concession, the distribution of mammal populations is much more influenced by the development of the logging road network and increased accessibility to hunters and poachers than by the direct effects of logging (Brodie et al., 2015; Robinson et al., 1999; van Vliet and Nasi, 2008). Increasing hunting pressure induces a steady decline in total biomass of all vertebrates, with a particularly rapid decline of large-bodied preferred game species such as primates and ungulates (Koerner et al., 2017; Poulsen et al., 2011), as found here. Only small rodents (Kurten, 2013) and other small generalist species (van Vliet and Nasi, 2008) could be more resilient to hunting pressure (Benítez-López et al., 2017; Koerner et al., 2017; Wright, 2003). Here, and as also observed by Laurance et al. (2006) in Gabon, the pangolin and small rodents are more abundant in logged forests and forests close to villages than in undisturbed forests. This can be due to the density compensation phenomenon resulting from the extirpation of competitive species (Peres and Dolman, 2000).

Each of the three forest allocations showed distinct dung beetle species composition, indicated by the high turnover component of beta diversity among sampled areas. Large dung beetle species were more abundant in the protected area than in the two other forest allocations. As revealed by our results, several studies also showed that humandriven forest disturbances impact dung beetle species composition, particularly by reducing the abundance of large-sized species (F.A. Edwards et al., 2014; Nichols et al., 2013). Our analyses showed the high local influence of proximity to roads and associated logging, agricultural and habitat disturbances on dung beetle species composition. Dung beetle species have been identified as indicators of closedcanopy forests (Watkins et al., 2017). Impoverished samples of the communities are obtained in any clearings created for road construction, largely degrading dung beetle habitat quality (Hosaka et al., 2014). Dung beetle community composition is also affected by forest fragmentation (Nichols et al., 2007), as seen here in degraded community forests impacted by agriculture and with relatively higher canopy openness. In contrast to mammals, dung beetles are known to be particularly sensitive to the environmental effects of selective logging (Bicknell et al., 2014). As shown here, a negative influence of roads on dung beetle populations has already been demonstrated up to $170 \mathrm{~m}$ into the forest interior due to micro-habitat variation, with associated declines of ecological functions (Edwards et al., 2017; Hosaka et al.,
2014) such as dung and seed removal (Andresen, 2003; Slade et al., 2011).

\subsection{Conservation value of forest allocations}

In the face of major environmental issues in Central Africa (Abernethy et al., 2016), our results confirmed the importance of protected areas in the conservation of large-bodied and threatened mammal species, as well as most forest dung beetle species (as also shown by Davis and Philips, 2005). Even if many protected tropical forests experience alarming biodiversity losses (Laurance et al., 2012), the long-term presence of conservation activities can reduce threats (Tranquilli et al., 2014). In the Dja Biosphere Reserve, conservation activities include law enforcement through anti-poaching patrols and awareness campaigns, scientific research, and tourism, which together can lower threats in African protected areas (Tranquilli et al., 2014). Additionally, in the northern sector of the Reserve motor vehicles cannot easily cross the Dja River reducing accessibility for commercial poachers.

We found that production forests can harbour similar species richness and composition to that of protected areas. Vulnerable pangolin species (Manis spp.) were even found more frequently in the logging concession than in the two other forest allocations (Appendix D). It has already been demonstrated that selective logging has modest impacts on most taxonomic groups (e.g., species richness of birds, mammals, invertebrates, and plants according to Putz et al., 2012) and only slightly reduces biodiversity levels (Clark et al., 2009; Gibson et al., 2011). In particular, Burivalova et al. (2014) suggested that most taxonomic groups would be resilient to selective logging at intensities lower than $10 \mathrm{~m}^{3} \mathrm{ha}^{-1}$, as applied in the FSC-certified concession studied here. However, here we reported high spatial heterogeneity of biodiversity in the logging concession that we related to local disturbances induced by roads. Indeed, as a side effect of logging, the road network can make some areas highly accessible and deeply impacted by human activities (logging, hunting and poaching), whereas remote areas remain nearly intact (Poulsen et al., 2009).

Community forests were found to be particularly depauperate, with a dominance of small-sized mammal species and poor dung beetle communities. The low conservation value of these forests is due to the high proximity to villages and roads (Beirne et al., 2019). Human presence is associated with hunting pressure, fire, and forest fragmentation induced by slash-and-burn agriculture. Yet some mammal species were found to be more abundant in these young secondary forests, such as the African palm civet (Nandinia binotata) that lives in umbrella trees (Musanga cecropioides). Community forests cannot yet be considered as totally defaunated, even though human populations intensively use them for a multitude of ecosystem services, including bushmeat provision (Lhoest et al., 2019).

\subsection{Conservation implications}

Our results confirm that the road network and associated forest accessibility have major detrimental effects on biodiversity. The area damaged by logging roads typically reaches 0.6 to $8.0 \%$ of forest area in tropical countries (Kleinschroth and Healey, 2017) and 1.26\% in the studied logging concession in 2018. Roads are a financially costly element of logging activities, and both concession holders and biodiversity conservation would benefit to improve the design and planning of logging roads (Edwards et al., 2017). It has been previously suggested to: (i) implement strategic planning and long-term spatial prioritization (Kleinschroth et al., 2019) in order to limit the size and expansion of logging road networks (Laurance et al., 2009; Putz et al., 2008); (ii) define a minimum volume of timber extracted per unit length of logging road to justify road construction (Edwards et al., 2017); (iii) close logging roads after timber extraction to facilitate forest recovery and discourage hunters from penetrating the forest (Bicknell et al., 2015; 
Clark et al., 2009; Kleinschroth et al., 2016); and (iv) avoid building any roads suitable for motor vehicles inside protected areas (such as in the Dja Biosphere Reserve) and only planning appropriate pedestrian access where needed.

Our study identified a strong decline of mammal species richness in proximity to villages in southeastern Cameroon. The hunting pressure surrounding rural communities is known to be extremely high in Cameroon. Several effective solutions must be implemented to halt the defaunation crisis in Central Africa, including: (i) law enforcement (Critchlow et al., 2017) comprising anti-poaching operations (BenítezLópez et al., 2017) and a better control of access in logging concessions and protected areas (van Vliet and Nasi, 2008); (ii) participatory repressive enforcement program (Beirne et al., 2019; Clark et al., 2009; Vermeulen et al., 2009); (iii) ban of hunting of sensitive species (according to the IUCN status) and regulation of hunting of the most resilient and locally abundant species such as the blue duiker (Philantomba monticola) or the African brush-tailed porcupine (Atherurus africanus) (Nasi et al., 2011; van Vliet and Nasi, 2008); (iv) provision of alternative sources of proteins (local fish farming, aviculture, supply of butcher's meat, vegetal proteins, edible insects) at affordable prices, with a minimization of their negative environmental impacts (Rentsch and Damon, 2013; Wilkie et al., 2005).

Conservation strategies have to be designed and coordinated at a large scale (landscape, national or continental scale) in balance with the need for economic development and bushmeat provision (Poulsen et al., 2011). High values of turnover among forest allocations for both mammal and dung beetle species in our results support a devotion of conservation initiatives to a large number of different sites, with a priority on protected and remote areas of high biodiversity. Production forests in the surroundings of protected areas have a crucial buffer role to play. In particular, adapted management aimed at minimizing the degradation of high conservation value forests is an important requirement of FSC certification. If strictly protected forest patches are not connected with production forests in a larger forest matrix, no conservation intervention is likely to be sufficient (D.P. Edwards et al., 2014). Connected to protected areas, production forests offer the chance to conserve many ecosystem services, functions, and species (Clark et al., 2009). They cover a high proportion of forest lands and show lower opportunity costs than protected areas. It is vital for biodiversity that protected and production forests be maintained as forest lands rather than being converted to agriculture or plantations characterized by much lower conservation values (Chazdon et al., 2009).

\section{Declaration of competing interest}

The work is all original research carried out by the authors. All authors agree with the content of the manuscript and its submission to the journal. No part of the research has been submitted nor published in any form in this journal or elsewhere. The manuscript is not being considered for publication elsewhere while it is being considered for publication in this journal. All sources of funding are acknowledged in the manuscript, and authors have no financial benefits that could result from publication.

\section{Acknowledgements}

The work of Simon LHOEST and Davy FONTEYN was supported by FRIA (F.R.S.-FNRS, grant numbers 5125916F and 5110318F). Field inventories benefited from the funding of the AFRITIMB project subsidized by the FRFS-WISD (grant number PDR-WISD-07) and the P3FAC project funded by FFEM (grant number CZZ2101.01R). Funding support was also provided by 'Fonds Léopold III pour l'Exploration et la Conservation de la Nature', Fédération Wallonie-Bruxelles, University of Liège, and 'Académie de Recherche et d'Enseignement Supérieur de la Fédération Wallonie-Bruxelles'. We thank Nature+ asbl, Oliver FANKEM from Zoological Society of London, the PALLISCO Company, the Conservation Service of the Dja Biosphere Reserve, and the management committees of the community forests of Medjoh, Avilso and Eschiambor for their logistic support. Acknowledgements are also due to Frédéric FRANCIS and Jeannine BORTELS for the dung beetles inventory, to Fructueux HOUNGBÉGNON, Henri ROBERT, René-Marie LAFONTAINE and Roseline C. BEUDELS-JAMAR DE BOLSÉE for mammal inventory, and to Michael D. SWAINE and Franck TROLLIET for proofreading the manuscript. We are grateful to John POULSEN and to an anonymous reviewer for their insightful comments and contributions. The authors have no competing interests.

\section{Appendix A. Supplementary data}

Supplementary data to this article can be found online at https:// doi.org/10.1016/j.biocon.2019.108351.

\section{References}

Abernethy, K., Maisels, F., White, L.J.T., 2016. Environmental issues in Central Africa Annu. Rev. Environ. Resour. 41, 1-33. https://doi.org/10.1146/annurev-environ110615-085415.

Abernethy, K.A., et al., 2013. Extent and ecological consequences of hunting in Central African rainforests in the twenty-first century. Philos. Trans. R. Soc. B 368, 20120303. https://doi.org/10.1098/rstb.2012.0303.

Ahumada, J.A., Hurtado, J., Lizcano, D., 2013. Monitoring the status and trends of tropical forest terrestrial vertebrate communities from camera trap data: a tool for conservation. PLoS One 8, e73707. https://doi.org/10.1371/journal.pone.0073707.

Andresen, E., 2003. Effect of forest fragmentation on dung beetle communities and functional consequences for plant regeneration. Ecography 26, 87-97. https://doi. org/10.1034/j.1600-0587.2003.03362.x.

Baselga, A., 2010. Partitioning the turnover and nestedness components of beta diversity. Glob. Ecol. Biogeogr. 19, 134-143. https://doi.org/10.1111/j.1466-8238.2009. 00490.x.

Baselga, A., Orme, C.D.L., 2012. betapart: an R package for the study of beta diversity. Methods Ecol. Evol. 3, 808-812. https://doi.org/10.1111/j.2041-210X.2012. 00224.x.

Beirne, C., et al., 2019. Participatory monitoring reveals village-centered gradients of mammalian defaunation in Central Africa. Biol. Conserv. 233, 228-238. https://doi. org/10.1016/j.biocon.2019.02.035.

Benítez-López, A., et al., 2017. The impact of hunting on tropical mammal and bird populations. Science 356, 180-183. https://doi.org/10.1126/science.aaj1891.

Berkes, F., Folke, Carl, Gadgill, M., 1994. Traditional ecological knowledge, biodiversity, resilience and sustainability, in: Perrings, C.A., Maler, K.G., Folke, C., Holling, C.S., Jansson, B.O. (Eds.), Biodiversity Conservation. Dordrecht, pp. 281-299.

Bicknell, J.E., et al., 2014. Dung beetles as indicators for rapid impact assessments: evaluating best practice forestry in the neotropics. Ecol. Indic. 43, 154-161. https:// doi.org/10.1016/j.ecolind.2014.02.030.

Bicknell, J.E., Gaveau, D.L.A., Davies, Z.G., Struebig, M.J., 2015. Saving logged tropical forests: closing roads will bring immediate benefits: peer-reviewed letter. Front. Ecol. Environ. 13, 73-74. https://doi.org/10.1890/15.WB.001.

Blomley, T., 2013. Lessons learned from community forestry in Africa and their relevance for REDD +. USAID-supported Forest Carbon, Markets and Communities (FCMC) Program, Washington, FC, USA.

Brodie, J.F., Giordano, A.J., Zipkin, E.F., Bernard, H., Mohd-Azlan, J., Ambu, L., 2015 Correlation and persistence of hunting and logging impacts on tropical rainforest mammals: logging, hunting, and mammal diversity. Conserv. Biol. 29, 110-121. https://doi.org/10.1111/cobi.12389.

Bruce, T., et al., 2018. Using camera trap data to characterise terrestrial larger-bodied mammal communities in different management sectors of the Dja Faunal Reserve, Cameroon. Afr. J. Ecol. 56, 759-776. https://doi.org/10.1111/aje.12574.

Burivalova, Z., Sekercioğlu, C., Koh, L.P., 2014. Thresholds of logging intensity to maintain tropical forest biodiversity. Curr. Biol. 24, 1893-1898. https://doi.org/10. 1016/j.cub.2014.06.065.

Cajaiba, R.L., Périco, E., da Silva, W.B., Santos, M., 2017. Can dung beetles (Scarabaeinae) indicate the status of Amazonia's ecosystems? Insights integrating anthropogenic disturbance with seasonal patterns. Anim. Biol. 67, 301-318. https:// doi.org/10.1163/15707563-00002538.

Chazdon, R.L., et al., 2009. Beyond reserves: a research agenda for conserving biodiversity in human-modified tropical landscapes. Biotropica 41, 142-153. https://doi. org/10.1111/j.1744-7429.2008.00471.x.

Clark, C.J., Poulsen, J.R., Malonga, R., ELKAN, Jr., P.W., 2009. Logging concessions can extend the conservation estate for Central African tropical forests. Conserv. Biol. 23 , 1281-1293. doi:https://doi.org/10.1111/j.1523-1739.2009.01243.x.

Cottenie, K., De Meester, L., 2003. Comment to Oksanen (2001): reconciling Oksanen (2001) and Hurlbert (1984). Oikos 100, 394-396. https://doi.org/10.1034/j.16000706.2003.11953.x.

Critchlow, R., et al., 2017. Improving law-enforcement effectiveness and efficiency in protected areas using ranger-collected monitoring data. Conserv. Lett. 10, 572-580. https://doi.org/10.1111/conl.12288.

Davis, A.L.V., Philips, T.K., 2005. Effect of deforestation on a Southwest Ghana dung 
beetle assemblage (Coleoptera: Scarabaeidae) at the periphery of Ankasa conservation area. Environ. Entomol. 34, 8.

Dirzo, R., Raven, P.H., 2003. Global state of biodiversity and loss. Annu. Rev. Environ. Resour. 28, 137-167. https://doi.org/10.1146/annurev.energy.28.050302.105532.

Duguma, L.A., et al., 2018. Community forestry frameworks in sub-Saharan Africa and the impact on sustainable development. Ecol. Soc. 23. https://doi.org/10.5751/ES 10514-230421.

Edwards, D.P., et al., 2014. Maintaining ecosystem function and services in logged tropical forests. Trends Ecol. Evol. 29, 511-520. https://doi.org/10.1016/j.tree.2014. 07.003.

Edwards, F.A., et al., 2014. Does logging and forest conversion to oil palm agriculture alter functional diversity in a biodiversity hotspot?: functional diversity and land-use change in Borneo. Anim. Conserv. 17, 163-173. https://doi.org/10.1111/acv.12074.

Edwards, F.A., et al., 2017. The impact of logging roads on dung beetle assemblages in a tropical rainforest reserve. Biol. Conserv. 205, 85-92. https://doi.org/10.1016/j. biocon.2016.11.011.

Fayolle, A., et al., 2014. Patterns of tree species composition across tropical African forests. J. Biogeogr. 41, 2320-2331. https://doi.org/10.1111/jbi.12382.

Gardner, T.A., et al., 2008. The cost-effectiveness of biodiversity surveys in tropical forests. Ecol. Lett. 11, 139-150. https://doi.org/10.1111/j.1461-0248.2007.01133.x.

Gardner, T.A., et al., 2009. Prospects for tropical forest biodiversity in a human-modified world. Ecol. Lett. 12, 561-582. https://doi.org/10.1111/j.1461-0248.2009.01294.x.

Gibson, L., et al., 2011. Primary forests are irreplaceable for sustaining tropical biodiversity. Nature 478, 378-381. https://doi.org/10.1038/nature10425.

Gotelli, N.J., Colwell, R.K., 2001. Quantifying biodiversity: procedures and pitfalls in the measurement and comparison of species richness. Ecol. Lett. 4, 379-391.

Hijmans, R.J., et al., 2005. Very high resolution interpolated climate surfaces for global land areas. Int. J. Climatol. 25, 1965-1978. https://doi.org/10.1002/joc.1276.

Hosaka, T., et al., 2014. Effects of logging road networks on the ecological functions of dung beetles in Peninsular Malaysia. For. Ecol. Manag. 326, 18-24. https://doi.org/ 10.1016/j.foreco.2014.04.004.

Hurlbert, S.H., 1984. Pseudoreplication and the design of ecological field experiments. Ecol. Monogr. 54, 187-211.

Kellert, S.R., Mehta, J.N., Ebbin, S.A., Lichtenfeld, L.L., 2000. Community natural resource management: promise, rhetoric, and reality. Soc. Nat. Resour. 13, 705-715. https://doi.org/10.1080/089419200750035575.

Kingdon, J, 2015. The Kingdon Field Guide to African Mammals. Bloomsbury Publishing.

Kingdon, J., et al., 2013. In: Black, A. (Ed.), Mammals of Africa. Bloomsbury Publishing, London.

Klein, B.C., 1989. Effects of forest fragmentation on dung and carrion beetle communities in Central Amazonia. Ecology 70, 1715-1725. https://doi.org/10.2307/1938106.

Kleinschroth, F., Healey, J.R., 2017. Impacts of logging roads on tropical forests Biotropica 49, 620-635. https://doi.org/10.1111/btp.12462.

Kleinschroth, F., Healey, J.R., Gourlet-Fleury, S., 2016. Sparing forests in Central Africa: re-use old logging roads to avoid creating new ones. Front. Ecol. Environ. 14, 9-10. https://doi.org/10.1002/FEEKleinscrothletter.1.

Kleinschroth, F., et al., 2019. Road expansion and persistence in forests of the Congo Basin. Nat. Sustain. 2, 628-634.

Koerner, S.E., et al., 2017. Vertebrate community composition and diversity declines along a defaunation gradient radiating from rural villages in Gabon. J. Appl. Ecol. 54, 805-814. https://doi.org/10.1111/1365-2664.12798.

Kurten, E.L., 2013. Cascading effects of contemporaneous defaunation on tropical forest communities. Biol. Conserv. 163, 22-32. https://doi.org/10.1016/j.biocon.2013.04. 025.

Larsen, T.H., Forsyth, A., 2005. Trap spacing and transect design for dung beetle biodiversity studies. Biotropica 37, 322-325. https://doi.org/10.1111/j.1744-7429.2005 00042.x.

Laurance, W.F., et al., 2006. Impacts of roads and hunting on central African rainfores mammals. Conserv. Biol. 20, 1251-1261. https://doi.org/10.1111/j.1523-1739. 2006.00420.x.

Laurance, W.F., Goosem, M., Laurance, S.G.W., 2009. Impacts of roads and linear clearings on tropical forests. Trends Ecol. Evol. 24, 659-669. https://doi.org/10.1016/j. tree.2009.06.009.

Laurance, W.F., et al., 2012. Averting biodiversity collapse in tropical forest protected areas. Nature 489, 290-294. https://doi.org/10.1038/nature11318.

Lê Cao, K.-A., González, I., Déjean, S., 2009. integrOmics: an R package to unravel relationships between two omics datasets. Bioinformatics 25, 2855-2856. https://doi. org/10.1093/bioinformatics/btp515.

Lescuyer, G., et al., 2019. Are community forests a viable model for the Democratic Republic of Congo? Ecol. Soc. 24. https://doi.org/10.5751/ES-10672-240106.

Lhoest, S., et al., 2019. Perceptions of ecosystem services provided by tropical forests to local populations in Cameroon. Ecosyst. Serv. 38, 100956. https://doi.org/10.1016/j. ecoser.2019.100956.

Malhi, Y., et al., 2014. Tropical forests in the Anthropocene. Annu. Rev. Environ. Resour. 39, 125-159. https://doi.org/10.1146/annurev-environ-030713-155141.

Maryudi, A., et al., 2012. Back to basics: considerations in evaluating the outcomes of community forestry. For. Policy Econ. 14, 1-5. https://doi.org/10.1016/j.forpol. 2011.07.017.

Mayaux, P., Bartholomé, E., Fritz, S., Belward, A., 2004. A new land-cover map of Africa for the year 2000. J. Biogeogr. 31, 861-877.

Minang, P.A., et al., 2019. Evolution of community forestry in Cameroon: an innovation ecosystems perspective. Ecol. Soc. 24. https://doi.org/10.5751/ES-10573-240101.

Nasi, R., Taber, A., Van Vliet, N., 2011. Empty forests, empty stomachs? Bushmeat and livelihoods in the Congo and Amazon Basins. Int. For. Rev. 13, 355-368. https://doi. org/10.1505/146554811798293872.

Nasi, R., Billand, A., Vanvliet, N., 2012. Managing for timber and biodiversity in the
Congo Basin. For. Ecol. Manag. 268, 103-111. https://doi.org/10.1016/j.foreco. 2011.04.005.

Nervo, B., et al., 2017. Ecological functions provided by dung beetles are interlinked across space and time: evidence from ${ }^{15} \mathrm{~N}$ isotope tracing. Ecology $98,433-446$. https://doi.org/10.1002/ecy.1653.

Nichols, E., et al., 2007. Global dung beetle response to tropical forest modification and fragmentation: a quantitative literature review and meta-analysis. Biol. Conserv. 137, $1-19$.

Nichols, E., et al., 2008. Ecological functions and ecosystem services provided by Scarabaeinae dung beetles. Biol. Conserv. 141, 1461-1474. https://doi.org/10.1016/ j.biocon.2008.04.011.

Nichols, E., Gardner, T.A., Peres, C.A., Spector, S., The Scarabaeinae Research Network, 2009. Co-declining mammals and dung beetles: an impending ecological cascade. Oikos 118, 481-487. https://doi.org/10.1111/j.1600-0706.2008.17268.x.

Nichols, E., et al., 2013. Human-induced trophic cascades along the fecal detritus pathway. PLoS One 8, e75819. https://doi.org/10.1371/journal.pone.0075819.

Nummelin, M., Hanski, I., 1989. Dung beetles of the Kibale Forest, Uganda; comparison between virgin and managed forests. J. Trop. Ecol. 5, 349-352. https://doi.org/10. $1017 /$ S0266467400003758.

Oksanen, J., et al., 2018. vegan: Community Ecology Package.

Oyono, P.R., et al., 2014. Allocation and use of forest land: current trends, issues and perspectives. In: de Wasseige, C., Flynn, J., Louppe, D., Hiol Hiol, F., Mayaux, P. (Eds.), The Forests of the Congo Basin - State of the Forest 2013, pp. 215-240 Neufchâteau, Belgique.

Panlasigui, S., et al., 2018. Impacts of certification, uncertified concessions, and protected areas on forest loss in Cameroon, 2000 to 2013. Biol. Conserv. 227, 160-166. https:// doi.org/10.1016/j.biocon.2018.09.013.

Peres, C.A., Dolman, P.M., 2000. Density compensation in neotropical primate communities: evidence from 56 hunted and nonhunted Amazonian forests of varying productivity. Oecologia 122, 175-189. https://doi.org/10.1007/PL00008845.

Poulsen, J.R., Clark, C.J., Mavah, G., Elkan, P.W., 2009. Bushmeat supply and consumption in a tropical logging concession in northern Congo. Conserv. Biol. 23 1597-1608. https://doi.org/10.1111/j.1523-1739.2009.01251.x.

Poulsen, J.R., Clark, C.J., Bolker, B.M., 2011. Decoupling the effects of logging and hunting on an Afrotropical animal community. Ecol. Appl. 21, 1819-1836. https:// doi.org/10.1890/10-1083.1.

Poulsen, J.R., Clark, C.J., Palmer, T.M., 2013. Ecological erosion of an Afrotropical forest and potential consequences for tree recruitment and forest biomass. Biol. Conserv. 163, 122-130. https://doi.org/10.1016/j.biocon.2013.03.021.

Poulsen, J.R., et al., 2018. Ecological consequences of forest elephant declines for Afrotropical forests: forest elephant declines. Conserv. Biol. 32, 559-567. https://doi org/10.1111/cobi.13035

Putz, F.E., Sist, P., Fredericksen, T., Dykstra, D., 2008. Reduced-impact logging: challenges and opportunities. For. Ecol. Manag. 256, 1427-1433. https://doi.org/10. 1016/j.foreco.2008.03.036

Putz, F.E., et al., 2012. Sustaining conservation values in selectively logged tropical forests: the attained and the attainable: sustaining tropical forests with forestry. Conserv. Lett. 5, 296-303. https://doi.org/10.1111/j.1755-263X.2012.00242.x.

R Core Team, 2018. R: A Language and Environment for Statistical Computing. R Foundation for Statistical Computing, Vienna, Austria.

Redford, K.H., 1992. The empty forest. BioScience 42, 412-422. https://doi.org/10. $2307 / 1311860$.

Rentsch, D., Damon, A., 2013. Prices, poaching, and protein alternatives: an analysis of bushmeat consumption around Serengeti National Park, Tanzania. Ecol. Econ. 91, 1-9. https://doi.org/10.1016/j.ecolecon.2013.03.021.

Ribot, J.C., 2003. Democratic decentralisation of natural resources: institutional choice and discretionary power transfers in Sub-Saharan Africa. Public Adm. Dev. 23, 53-65. https://doi.org/10.1002/pad.259.

Robinson, J.G., Redford, K.H., Bennett, E.L., 1999. Wildlife harvest in logged tropical forests. Science 284, 595-596. https://doi.org/10.1126/science.284.5414.595.

Rowcliffe, J.M., et al., 2011. Quantifying the sensitivity of camera traps: an adapted distance sampling approach: quantifying camera trap sensitivity. Methods Ecol. Evol. 2, 464-476. https://doi.org/10.1111/j.2041-210X.2011.00094.x.

Slade, E.M., Mann, D.J., Lewis, O.T., 2011. Biodiversity and ecosystem function of tropical forest dung beetles under contrasting logging regimes. Biol. Conserv. 144 166-174. https://doi.org/10.1016/j.biocon.2010.08.011.

Sonké, B., 1998. Études floristiques et structurales des forêts de la Réserve de Faune du Dja (Cameroun) (Thèse de doctorat). Université Libre de Bruxelles, Faculté des Sciences, Laboratoire de Botanique Systématique et de Phytosociologie, Bruxelles, Belgique.

TEAM Network, 2011. Terrestrial vertebrate (camera trap) monitoring protocol implementation manual.

Terborgh, J., et al., 2008. Tree recruitment in an empty forest. Ecology 89, 1757-1768. https://doi.org/10.1890/07-0479.1.

Tobler, M.W., 2015. Camera Base Version 1.7, User guide. Retrieved from. http://www. atrium-biodiversity.org/tools/camerabase/.

Tobler, M.W., et al., 2008. An evaluation of camera traps for inventorying large- and medium-sized terrestrial rainforest mammals. Anim. Conserv. 11, 169-178. https:// doi.org/10.1111/j.1469-1795.2008.00169.x.

Tranquilli, S., et al., 2014. Protected areas in tropical Africa: assessing threats and conservation activities. PLoS One 9, e114154. https://doi.org/10.1371/journal.pone. 0114154.

Vermeulen, C., Julve, C., Doucet, J.-L., Monticelli, D., 2009. Community hunting in logging concessions: towards a management model for Cameroon's dense forests. Biodivers. Conserv. 18, 2705-2718. https://doi.org/10.1007/s10531-009-9614-6.

van Vliet, N., Nasi, R., 2008. Hunting for livelihood in northeast Gabon: patterns, 
evolution, and sustainability. Ecol. Soc. 13. https://doi.org/10.5751/ES-02560130233.

Watkins, E., Kitching, R.L., Nakamura, A., Stork, N.E., 2017. Beetle assemblages in rainforest gaps along a subtropical to tropical latitudinal gradient. Biodivers. Conserv. 26, 1689-1703. https://doi.org/10.1007/s10531-017-1326-8.

Watson, J.E.M., Dudley, N., Segan, D.B., Hockings, M., 2014. The performance and potential of protected areas. Nature 515, 67-73. https://doi.org/10.1038/nature13947.

Wilkie, D.S., et al., 2005. Role of prices and wealth in consumer demand for Bushmeat in Gabon, Central Africa. Conserv. Biol. 19, 268-274. https://doi.org/10.1111/j.1523- 1739.2005.00372.x.

Wittemyer, G., et al., 2008. Accelerated human population growth at protected area edges. Science 321, 123-126.

Wright, S.J., 2003. The myriad consequences of hunting for vertebrates and plants in tropical forests. Perspect. Plant Ecol. Evol. Syst. 6, 73-86. https://doi.org/10.1078/ 1433-8319-00043.

Ziegler, S., et al., 2016. Mapping bushmeat hunting pressure in Central Africa. Biotropica 48, 405-412. https://doi.org/10.1111/btp.12286. 